\title{
Letter \\ Is "safe effective glucose control" effective and safe?
} Marcus J Schultz ${ }^{1,2}$ and Greet Van den Berghe ${ }^{3}$

\author{
${ }^{1}$ Department of Intensive Care, Academic Medical Center, University of Amsterdam, 1105 AZ Amsterdam, the Netherlands \\ ${ }^{2}$ Laboratory of Experimental Intensive Care and Anesthesiology (L.E.I.C.A), Academic Medical Center, University of Amsterdam, 1105 AZ Amsterdam, \\ the Netherlands \\ ${ }^{3}$ Department of Intensive Care, Catholic University Leuven, Leuven, Belgium
}

Corresponding author: Marcus J Schultz, m.j.schultz@amc.uva.nl

Published: 6 August 2008

This article is online at http://ccforum.com/content/12/4/424

(c) 2008 BioMed Central Ltd

See related commentary by Krinsley and Preiser, http://ccforum.com/content/12/3/149

Since tight glucose control (TGC) inevitably comes with a risk of hypoglycemia, Krinsley and Preiser [1] suggest the use of a stepwise approach to glucose control, which they call "safe, effective glucose control" (SEGC), and that targets an intermediate blood glucose level (BGL). SEGC is intended to decrease the rate of hyperglycemia while reducing the adverse effects of severe hypoglycemia.

Of note, the randomized controlled trials that showed a benefit from glucose control have tested only one and the same $B G L$ target $(4.4$ to $6.1 \mathrm{mmol} / \mathrm{l}$ [80 to $110 \mathrm{mg} / \mathrm{dl}]$ ) $[2,3]$. In addition, in these trials conventional insulin treatment was administered only when the BGL was $>12 \mathrm{mmol} / \mathrm{L}$ (215 $\mathrm{mg} / \mathrm{dl})$, with insulin infusion gradually decreased and stopped when the $B G L$ fell to $<10 \mathrm{mmol} / \mathrm{l}(180 \mathrm{mg} / \mathrm{dl})$. Accordingly, the average morning $\mathrm{BGL}$ of the conventional treatment group was approximately $8.5 \mathrm{mmol} / \mathrm{l}(150 \mathrm{mg} / \mathrm{dl})$. Therefore, it is difficult to understand why this level is now the recommended BGL target in what Krinsley and Preiser label "safe" and "effective" glucose control. Avoiding hypoglycemia may definitely be "safe", but advocating a target similar to the control group of the two trials has definitely not been shown to be "effective" in improving outcome. It is incorrect advice in the light of evidence-based medicine (there simply is no evidence for the benefit of using higher BGL targets) and could adversely lead to more patients with higher BGLs, which would eventually worsen outcome [4].

Severe and prolonged hypoglycemia can cause complications and mortality. Hypoglycemia also occurs more often in the most severely ill patients and those who have a long intensive care unit (ICU) stay, but this association does not suffice to conclude that it actually causes death. Solid evidence, indeed, for a causal relationship between TGCinduced brief hypoglycemia in the ICU setting and risk of death is lacking. In contrast, a retrospective nested casecontrol study that carefully matched for type and severity of illness as well as duration of ICU stay and, thus, for exposure time to insulin infusions suggested no causal relationship between hypoglycemia and mortality [5]. Recently, experimental data indicated that glucose reperfusion, rather than hypoglycemia itself, is the cause of neuronal damage [6]. Hence, not the period of hypoglycemia itself, but the (over)correction with intravenous dextrose may be most harmful.

The advice to tolerate higher BGLs in ICU patients as if this would be "effective to reduce mortality" and "safer" and, thus, preferable over TGC with a BGL target of 4.4 to $6.1 \mathrm{mmol} / \mathrm{l}$ (80 to $110 \mathrm{mg} / \mathrm{dl}$ ) is not based on evidence.

\section{Authors' response}

James S Krinsley and Jean-Charles Preiser

Having read the letter to the editor of Schultz and Greet Van den Berghe in response to our commentary on "safe effective glucose control" [1], we feel it is important to clarify some issues.
The intention of our proposal was not to advocate targeting a high BGL in critically ill patients. Instead, review of the disappointing results of recent prospective trials of tight glucose control [7] suggests that the outstanding results achieved in

$\mathrm{BGL}=$ blood glucose level; ICU = intensive care unit; $\mathrm{SEGC}=$ safe, effective glucose control; TGC = tight glucose control. 
the first Leuven study are not achievable in many other clinical contexts because of the difficulty in achieving euglycemia without adverse safety concerns.

The suggestion of $150 \mathrm{mg} / \mathrm{dl}$ as the highest acceptable BGL was based on retrospective studies that reported an increased mortality in patients having a higher mean blood glucose during the ICU stay. This target was not tested in the published interventional studies, but achieved incidentally.

The risks associated with hypoglycaemia during critical illness are incompletely understood and have been shown to independently confer increased risk of mortality [8]. Indeed, intensive insulin therapy has been associated with lower cerebral (microdialysis) than blood glucose levels, and with increases in the concentration of markers of cellular distress [9].

Having the 'primum non nocere' of our Grandfather Hippocrates in mind, the proposed stepwise approach to glucose control will be easier to implement, certainly safer, and possibly effective, by the avoidance of the severe side effects of severe hyperglycemia. As monitoring technology improves it will be possible for more ICU teams to achieve the 'sweet spot ' of euglycemia.

\section{Competing interests}

The authors declare that they have no competing interests.

\section{References}

1 Krinsley JS, Preiser J-C: Moving beyond tight glucose control to safe effective glucose control. Crit Care 2008, 12:149.

2 Van den Berghe G, Wouters $P$, Weekers F, Verwaest C, Bruyninckx F, Schetz M, Vlasselaers D, Ferdinande P, Lauwers P, BouilIon R: Intensive insulin therapy in the critically ill patients. $N$ Engl J Med 2001, 345:1359-1367.

3 Van den Berghe G, Wilmer A, Hermans G, Meersseman W, Wouters PJ, Milants I, Van Wijngaerden E, Bobbaers H, Bouillon $\mathrm{R}$ : Intensive insulin therapy in the medical ICU. N Engl J Med 2006, 354:449-461.

4 Finney SJ, Zekveld C, Elia A, Evans TW: Glucose control and mortality in critically ill patients. JAMA 2003, 290:2041-2047.

5 Vriesendorp TM, DeVries JH, van Santen S, Moeniralam HS, de Jonge E, Roos YB, Schultz MJ, Rosendaal FR, Hoekstra JB: Evaluation of short-term consequences of hypoglycemia in an intensive care unit. Crit Care Med 2006, 34:2714-2718.

6 Suh SW, Gum ET, Hamby AM, Chan PH, Swanson RA: Hypoglycemic neuronal death is triggered by glucose reperfusion and activation of neuronal NADPH oxidase. J Clin Invest 2007, 117:910-918

7. Merz TM, Finfer S: Pro/con debate: Is intensive insulin therapy targeting tight blood glucose control of benefit in critically ill patients? Crit Care 2008, 12:212.

8. Krinsley JS, Grover A: Severe hypoglycemia in critically ill patients: risk factors and outcomes. Crit Care Med 2007, 35: 2262-2267.

9. Vespa P, Boonyaputthikul R, McArthur DL, Miller C, Etchepare M, Bergsneider M, Glenn T, Martin N, Hovda D: Intensive insulin therapy reduces microdialysis glucose values without altering glucose utilization or improving the lactate/pyruvate ratio after traumatic brain injury. Crit Care Med 2006, 34:850-856. 